\title{
RUMSFELD REVISITED: LA TERCERA ESTRATEGIA DE COMPENSACIÓN ESTADOUNIDENSE
}

\author{
Guillem Colom ${ }^{1}$ \\ THIBER
}

\begin{abstract}
Resumen:
El pasado noviembre, el ex Secretario de Defensa estadounidense Chuck Hagel lanzó la tercera estrategia de compensación. Enfocada a explotar las capacidades tecnológicas del país, esta iniciativa pretende incrementar la brecha de capacidades entre Estados Unidos y sus potenciales adversarios y garantizar la capacidad para proyectar el poder en cualquier punto del planeta con independencia de las medidas anti-acceso y de negación de área enemigas. El artículo analiza las características y potenciales efectos de esta estrategia cuyos pilares son muy similares a los planes transformadores que el ex titular de Defensa Donald Rumsfeld intentó implementar en 2001 y cuya conquista guiará el planeamiento de la defensa del país en los años venideros.
\end{abstract}

Palabras clave: estrategia de compensación, Estados Unidos, China, A2/AD, anti-acceso, negación de área, defensa, revolución en los asuntos militares.

Title in English: "Rumsfeld Revisited: The US Third Offset Strategy"

\begin{abstract}
:
Last November, the former Secretary of Defense Chuck Hagel launched the third offset strategy. Based on the exploitation of the American technological advantages, this initiative is aimed at widening the military gap between the United States and its prospective adversaries while ensuring the capability to project its military power everywhere around the globe regardless of the enemy's anti-access and area denial strategies. This article analyses the characteristics and potential effects of this strategy whose pillars resemble the transformation plans that ex Secretary Rumsfeld tried to implement un 2001 and whose achievement will guide the country's defence planning in the years to come.
\end{abstract}

Keywords: Offset strategy, Unites States, China, A2/AD, anti-access, area-denial, defence, revolution in military affairs.

Copyright @ UNISCI, 2015.

Las opiniones expresadas en estos artículos son propias de sus autores, y no reflejan necesariamente la opinión de UNISCI. The views expressed in these articles are those of the authors, and do not necessarily reflect the views of UNISCI.

\footnotetext{
${ }^{1}$ Guillem Colom Piella es codirector de THIBER, the cybersecurity think tank y profesor del área de Ciencia Política y de la Administración de la Universidad Pablo de Olavide (Sevilla).

Email: guillem.colom@thiber.org
} 


\section{Introducción}

Tras demorar su presentación durante más de un año, en marzo de 2014 el Pentágono aprobó la Revisión Cuadrienal de la Defensa (QDR) para establecer las líneas maestras de la política de defensa y la administración militar estadounidenses para el periodo 2014-18². Fundamentada en los preceptos establecidos por la Guía Estratégica de la Defensa que el Presidente Barack Obama lanzó en 2012 para cerrar definitivamente la Guerra contra el Terror y apoyar la transición estratégica hacia la región Asia-Pacífico ${ }^{3}$ y el Concepto Cardinal para las Operaciones Conjuntas que la élite militar del país elaboró para orientar la generación de nuevas capacidades bélicas ${ }^{4}$, esta hoja de ruta fija las pautas para "...adaptar, remodelar y recalibrar las fuerzas armadas para anticipar los cambios estratégicos y explotar las oportunidades que se nos presentarán en los próximos años" ${ }^{5}$ mientras se garantiza el liderazgo internacional estadounidense.

A los cinco meses de presentar la QDR 2014, el Panel de Defensa Nacional - un selecto grupo de expertos constituido ad hoc para evaluar las líneas maestras trazadas por esta revisión - emitía un amargo informe donde alertaba de que los continuados recortes en el gasto de militar comprometían su seguridad nacional; que el entorno internacional era cada vez más inestable y que la difusión de tecnologías avanzadas estaba reduciendo la brecha militar entre Estados Unidos y sus competidores ${ }^{6}$. En consecuencia, el informe no sólo recomendaba incrementar el presupuesto militar y mantener los volúmenes de fuerza previos al 11 de Septiembre de $2001^{7}$; sino también lanzar un nuevo proceso de innovación científicotecnológica que permitiera ampliar la brecha militar con sus adversarios y sentar las bases de una nueva Revolución en los Asuntos Militares (RMA) ${ }^{8}$. Precisamente, esta idea articularía el

\footnotetext{
2 Department of Defense (2014): "Quadrennial Defense Review 2014", Washington DC, U.S. Government Printing Office.

${ }^{3}$ Department of Defense (2012): "Sustaining U.S. Global Leadership: Priorities for $21^{\text {st }}$ Century Defense", Washington DC, U.S. Government Printing Office. Aunque este informe fijó las líneas maestras de la política de defensa y la organización militar estadounidense para la posguerra contra el terror y ratificó la transición del país hacia Asia-Pacífico, su valor legislativo es nulo. De hecho, construye una hoja de ruta que el ejecutivo demócrata elaboró ad hoc para presentar un plan de ajuste previo al debate sobre los presupuestos de 2013 y bloquear la acción de la cámara baja, controlada por el Partido Republicano. No obstante, el grueso de sus contenidos ya se han formalizado políticamente en la QDR 2014 y en la Estrategia Nacional de Seguridad presentada el pasado febrero. Por otro lado, en el plano militar, muchas de sus provisiones habían sido insinuadas en la Estrategia Nacional Militar (2011); codificadas en el Concepto Cardinal para las Operaciones Conjuntas (2012) y articuladas en el presupuesto federal de 2015. Un análisis más detallado de los planteamientos recogidos en este documento puede hallarse en: Dale, Catherine y Towell, Pat (2012): "Assessing DoD's New Strategic Guidance", Washingon DC, Congressional Research Service.

${ }^{4}$ Joint Chiefs of Staff (2012): "Capstone Concept for Joint Operations: Joint Force 2020", Washington DC, U.S. Government Printing Office. No obstante, esta hoja de ruta que fija los principios para el empleo de la fuerza conjunta y establece las orientaciones para el desarrollo de nuevos conceptos operativos y la generación de las capacidades futuras - que deberían replantearse a raíz del lanzamiento de la estrategia de compensación y de la iniciativa de innovación en defensa - también se fundamenta en las provisiones de la Estrategia Militar Nacional (2011).

${ }^{5}$ Palabras del Secretario de Defensa Chuck Hagel en la carta de promulgación de la QDR, 4 de marzo de 2014.

${ }^{6}$ National Defense Panel (2014): "Ensuring a Strong U.S. Defense for the Future - The National Defense Panel Review of the 2014 Quadrennial Defense Review", Washington DC, U.S. Institute for Peace.

${ }^{7}$ Mientras la QDR 2001 proponía una Fuerza Total - la suma del elemento activo, la reserva y la Guardia Nacional - de 2.246.000 efectivos (1.382.000 activos y 864.000 de reserva); la QDR 2014 plantea para 2019 un objetivo de 2.051.900 efectivos (1.254.000 activos y 798.000 de reserva) (Ibid., pp. 55-57).

${ }^{8}$ Una RMA es un cambio en la forma de combatir que, motivado por la explotación de nuevos sistemas de armas, conceptos operativos, doctrinas de empleo de la fuerza o maneras de organizar y administrar los medios materiales, convierte en obsoleto el estilo militar anterior. En la década de 1990, esta idea articuló el análisis esratégico internacional y el planteamiento de la defensa estadounidense, puesto que se asumía que esta revolución - posibilitada por las teconologías de la información, fundamentada en la obtención de un pleno reconocimiento de campo de batalla y configurada en torno a la generación de una fuerza conjunta capaz de
} 
discurso que el ex Secretario de Defensa Chuck Hagel dictó el pasado 3 de Septiembre y que sirve como punto de partida para la tercera estrategia de compensación (Third Offset Strategy), que pretende aprovechar - tal y como hizo la primera con la explotación de la brecha nuclear que existía entre Estados Unidos y la Unión Soviética en la década de 1950 y que motivó la represalia masiva o como planteó la segunda con el aprovechamiento de las tecnologías de la información para alterar el balance de fuerzas europeo en la década de $1970^{9}$ - las capacidades tecnológicas estadounidenses para resolver los problemas estratégicos que el país debe afrontar en la actualidad ${ }^{10}$.

Sin embargo, no sería hasta Noviembre cuando el titular del Pentágono emprendió la Iniciativa de Innovación en Defensa ${ }^{11}$ con el objetivo de generar nuevas capacidades militares y flexibilizar la administración militar del país ${ }^{12}$, anunció lanzamiento de un nuevo Programa para la Investigación y Desarrollo a Largo Plazo para identificar las tecnologías emergentes en el horizonte $2030^{13}$ y declaró que su departamento había comenzado a desarrollar esta estrategia para garantizar su supremacía militar futura ${ }^{14}$. Sin ninguna duda, la tercera offset será la gran herencia de Chuck Hagel tras su fugaz paso por el Pentágono, puesto que su consecución no sólo articulará el planeamiento de la defensa estadounidense durante la próxima década; sino que podría motivar el logro de una nueva RMA.

Teniendo en cuenta estos elementos, el trabajo estudiará la naturaleza y potenciales efectos de esta estrategia de compensación lanzada por Washington para incrementar su brecha tecnológico-militar frente a sus potenciales adversarios, garantizar la capacidad de proyección de sus ejércitos a cualquier punto del globo y contribuir al mantenimiento del liderazgo estadounidense en los asuntos internacionales. Como podrá observarse a lo largo del

dominar las esferas terrestre, naval, aéra, espacial y ciberespacial - permitiría incrementar la brecha militar entre Estados Unidos y sus adversarios y contribuir al mantenimiento de su hegemonía política (Colom, Guillem (2008): Entre Ares y Atenea: el debate sobre la Revolución en los Asuntos Militares, Madrid, Instituto Universitario General Gutiérrez Mellado).

${ }^{9}$ Aunque existen varios trabajos que analizan la estrategia New Look por la cual el Presidente Eisenhower logró reducir el montante total de la defensa estadounidense incrementando la capacidad de disuasión o el conjunto de medidas que el Pentágono implementó tras la debacle de Vietnam para recuperar la iniciativa perdida en Europa y cuyo desarrollo motivó la popularización de la RMA de la información, todavía son pocos los trabajos que analicen estos desarrollos en clave de primera y segunda offset. Para conocer con más detalle estas dos iniciativas, véase: Martinage, Robert (2014): Toward a New Offset Strategy: Exploiting U.S. Long-Term Advantages to Restore U.S. Global Power Projection Capability, Washington DC, Center for Strategic and Budgetary Assessments, pp. 5-16.

10 Más precisamente, el titular del Pentágono alertó de que "...las tecnologías disruptivas y las armas destructivas que antes sólo estaban en manos de los estados más avanzados han proliferado y están siendo adquiridas por países en desarrollo y grupos terroristas. Además, países como Rusia o China no sólo han reducido la brecha tecnológica con Estados Unidos e implementando ambiciosos programas de modernización militar a largo plazo, sino también están dotándose de capacidades antibuque, antisatélite, misiles de crucero, cibernéticas, guerra electrónica u operaciones especiales para contrarrestar nuestras tradicionales ventajas, en particular nuestra capacidad para proyectar nuestro poder a cualquier región del planeta." Discurso del Secretario de Defensa Chuck Hagel en la apertura de los "Defense Innovation Days" (Newport, 3 de septiembre de 2014).

${ }^{11}$ Office of the Secretary of Defense: The Defense Innovation Initiative (OSD-013411-14) (15 de noviembre de 2014).

12 Una capacidad militar se refiere al producto resultante de la integración de Doctrina, Organización, Adiestramiento, Material, Liderazgo y Educación, Personal e Infraestructuras (DOTMLPF) (Joint Chiefs of Staff (2015): Joint Publication 1-02: Department of Defense Dictionary of Military and Associated Terms, Washington DC, Department of Defense, p. A-51).

${ }^{13}$ Sin embargo, la recepción de propuestas tecnológicas e industriales se abrió en Enero y el planeamiento arrancará en Julio, que es cuando formalmente termina el Programa para la Investigación y Desarrollo a Largo Plazo que se inició en el año 2000.

${ }^{14}$ Discurso del Secretario de Defensa Chuck Hagel en la apertura del "Reagan National Defense Forum" (Simy Valley, 15 de noviembre de 2014). 
trabajo, muchos de los antecedentes conceptuales de esta iniciativa no sólo se trazaron en el Panel de Defensa Nacional de $1997^{15}$ - constituido para evaluar la QDR que el Presidente Clinton había presentado pocos meses antes ${ }^{16}$ - sino que estaban en el epicentro de los planes transformadores que el denostado Secretario de Defensa Donald Rumsfeld intentó implementar tras su llegada al Pentágono en 2001 con el fin de conquistar la RMA.

\section{2. ¿Por qué una nueva estrategia de compensación?}

Desde el fin del orden internacional bipolar, Estados Unidos ha realizado profundos cambios en su arquitectura defensiva para mantener su liderazgo global en un entorno estratégico en constante evolución ${ }^{17}$. En la inmediata posguerra fría éstos se orientaron a adaptar su entramado militar a la disipación de la amenaza soviética y a la conquista de una RMA que prometía garantizar la supremacía militar futura del país. Los sucesos del 11 de Septiembre de 2001 mediaron para que la transformación, inicialmente entendida como el proceso mediante el cual se conquistaría esta revolución y se prepararían las fuerzas armadas heredadas de la Guerra Fría a los retos del siglo XXI, se convirtiera en un imperativo estratégico para enfrentar con éxito los nuevos peligros para la paz y la seguridad internacionales. A pesar de los triunfos iniciales, las campañas afgana e iraquí revelaron tanto las carencias de la revolución como los límites de la transformación en ambientes de baja y media intensidad. Ello obligó a replantear la defensa del país para centrarse en la resolución de los problemas surgidos durante la Guerra contra el Terror - como las labores de estabilización, apoyo militar a la reconstrucción, lucha contra la insurgencia o antiterrorismo - en detrimento de prepararse para los conflictos futuros. La eliminación de Osama Bin Laden terminó de facto con la Guerra contra el Terror ${ }^{18}$, permitió adelantar los repliegues de Iraq y Afganistán y sustituir el modelo estratégico vigente por orto nuevo que, construido en oposición al reinante durante la Guerra contra el Terror, fundamentado en la herencia de la RMA y acorde con la cultura estratégica estadounidense, se orienta nuevamente hacia el mantenimiento de la supremacía militar convencional frente a cualquier adversario futuro ${ }^{19}$.

Condicionado por la redefinición de la estructura del poder global, la proliferación de nuevos riesgos a la seguridad, la reducción de la brecha militar con sus rivales y la crisis financiera que atraviesa Estados Unidos, este modelo estratégico intentará acomodar la arquitectura de seguridad del país al entorno internacional actual, reducir el montante de su defensa y mantener tanto la supremacía de sus ejércitos en el campo de batalla como la

\footnotetext{
${ }^{15}$ National Defense Panel (1997): Transforming Defense: National Security in the $21^{\text {st }}$ Century, Washington DC, Department of Defense.

16 Department of Defense (1997): Quadrennial Defense Review 1997, Washington DC, U.S. Government Printing Office.

${ }^{17}$ Colom, Guillem: "Cambio y continuidad en el pensamiento estratégico estadounidense desde el final de la Guerra Fría", Revista de Ciencia Política, vol. 33 n 3 (Diciembre 2013), pp. 675-92.

${ }^{18}$ En sentido estricto, la Guerra contra el Terror se eliminó del léxico estadounidense tras la elección del presidente Obama, siendo reemplazada por los conceptos Overseas Contingency Operation, usado en las declaraciones públicas y en la justificación del gasto de misiones, War Against Al Qaeda, presente en la Estrategia Nacional de Seguridad (2010) o Global Counterterrorism Operations utilizado en la Revisión Cuatrienal de la Defensa (2014) y ratificado en la Estrategia Nacional de Seguridad (2015) para definir uno de los cometidos de las fuerzas armadas del país. No obstante, Al Qaeda, Daesh u otras organizaciones yihadistas continúan siendo calificadas por Washington como una amenaza, tal y como lo atestiguan los distintos documentos oficiales y las declaraciones políticas.

19 Colom, Guillem: "La seguridad y defensa estadounidenses tras la guerra contra el terror", Colombia Internacional, $\mathrm{n}^{\circ} 81$ (Agosto 2014), pp. 267-290.
} 
capacidad para proyectar globalmente su $\operatorname{poder}^{20}$. Y para ello, Washington está empezando a reducir su presencia avanzada por los costes económicos, operativos y políticos que ésta entraña, por el riesgo que suponen para sus ejércitos las estrategias anti-acceso y de negación de área $(\mathrm{A} 2 / \mathrm{AD})^{21}$ y por el adelgazamiento de la estructura de fuerzas, y la restante se concentrará en Asia-Pacífico para demostrar el compromiso estadounidense con sus socios estratégicos. También ha abandonado los despliegues de fuerzas masivos y descartado conducir grandes campañas o embarcarse en labores de cambio de régimen, gestión de crisis, estabilización, apoyo militar a la reconstrucción o lucha contra la insurgencia y está mostrando un limitado interés en colaborar con las organizaciones multilaterales de seguridad $^{22}$. Ello será reemplazado por un progresivo repliegue en materia exterior ${ }^{23}$ que se combinará con la priorización de la inteligencia prospectiva mediante Internet y big data, la vigilancia global a tiempo real con satélites y drones y el ataque estratégico de precisión con bombarderos invisibles, sistemas no-tripulados y misiles. Además, Washington incrementará las colaboraciones ad hoc con terceros países, limitará sus compromisos defensivos en las regiones estratégicamente relevantes y concentrará su disuasión extendida en aquellas zonas donde el país tenga intereses vitales y quiera evitar un dilema de seguridad susceptible de provocar una escalada de tensión y una carrera de $\operatorname{armamentos}^{24}$. A ello se le sumará la conducción de acciones limitadas en tiempo, espacio y medios empleados; la negativa a mantener grandes despliegues en áreas avanzadas y la renuencia a desplegar unidades terrestres en zonas de conflicto; la multiplicación de las acciones contraterroristas empleando la nueva tríada estratégica (fuerzas de operaciones especiales, armamento inteligente y drones) o la priorización de la capacidad para conducir operaciones globales integradas sin ninguna limitación física, geográfica, temporal, orgánica o jerárquica en los cinco dominios del entorno operativo (tierra, mar, aire, espacio y ciberespacio).

En el corazón de este nuevo paradigma cuyos pilares comenzaron a perfilarse en la Guía Estratégica de la Defensa (2012) y codificarse en la Revisión Cuatrienal de la Defensa (2014) se halla la tercera estrategia de compensación. Fundamentada en el legado de la RMA de la información $^{25}$ y en la inventiva de la industria estadounidense ${ }^{26}$, este proceso de innovación

${ }^{20}$ VV.AA. (2012): New U.S. Defense Strategy for a New Era: Military Superiority, Agility and Efficiency. Washington DC, Stimson y Kugler, Richard (2011): New Directions in U.S. National Security Strategy, Defense Plans and Diplomacy. Washington DC, NDU Press.

${ }^{21}$ En términos generales, mientras las estrategias anti-acceso pretenden dificultar el despliegue de fuerzas en el teatro de operaciones, las de negación de área buscan dificultar la conducción de operaciones en zonas donde el adversario no impide el acceso. Aunque no pueden calificarse como algo novedoso porque han sido una preocupación latente de los estrategas estadounidenses desde la Administración Clinton, la proliferación de sistemas antiaéreos avanzados, misiles antibuque, misiles de crucero, armas antisubmarinas, aviones de caza y una amplia gama de medios asimétricos por parte de países como China o Irán están obligando a Washington a plantear cómo proyectar el poder en estos ambientes (Krepinevich, Andrew; Watts, Barry y Work, Robert (2003): Meeting the Anti-Access and Area-Denial Challenge, Washington DC, Center for Strategic and Budgetary Assessments).

${ }^{22}$ De hecho, las operaciones de estabilización y contrainsurgencia, las labores de apoyo a las autoridades civiles y las acciones de asistencia humanitaria y respuesta a desastres son la antepenúltima, penúltima y última misiones de la fuerza conjunta ("Quadrennial Defense...", op. cit., p. 61).

${ }^{23}$ Posen, Barry (2014): Restraint: A new Foundation for U.S. Grand Strategy, Ithaca, Cornell University Press.

${ }^{24}$ Martinage, op. cit., pp. 33-36.

${ }^{25}$ Ibid., pp. 13-25.

${ }^{26}$ Aunque esta idea ya estaba presente en la Guía Estratégica de la Defensa de 2012, en la tercera offset esta ha adquirido una importancia vital. Y es que si bien tradicionalmente la mayoría de los avances tecnológicos procedían del ámbito militar - y en el caso estadounidense, de la Agencia de Investigación de Proyectos de Defensa Avanzados (DARPA), cuyos desarrollos tecnológicos son fundamentales para comprender la RMA de la información - hoy muchas de las tecnologías potencialmente revolucionarias (robótica, guía remota, visualización, biotecnología, miniaturización, computación avanzada y big data o impresión 3D) proceden del sector civil (Harrison, Adam: "Offset 3.0, or: How I Learned to Stop Worrying and Love Commercial 
militar susceptible de motivar la consolidación de una nueva Revolución en los Asuntos Militares en las próximas décadas ${ }^{27}$ pretende resolver los interrogantes estratégicos del país en la posguerra contra el terror y mantener el mismo nivel de ambición militar con menos recursos económicos, humanos o materiales y mayores constricciones políticas. Más concretamente, la estrategia pretende incrementar la capacidad estadounidense para proyectar su poder bélico en entornos $\mathrm{A} 2 / \mathrm{AD}$, reforzar la disuasión convencional e imponer un elevado coste de oportunidad a los potenciales adversarios que pretendan competir con el país en materia tecnológica ${ }^{28}$.

¿Y cuáles son los principales interrogantes estratégicos que debe resolver Estados Unidos? En primer lugar, tal y como insinúa la Revisión Cuatrienal de la Defensa, alerta el Panel de Defensa Nacional y reconoce la comunidad militar estadounidense ${ }^{29}$, las fuerzas armadas del país difícilmente podrían combatir en dos guerras que estallaran de forma simultánea $^{30}$; por lo que serían incapaces de satisfacer uno de sus tradicionales objetivos de seguridad nacional ${ }^{31}$. Si a ello se le añade que el volumen y la estructura de fuerzas proyectada para el año 2019 - cuando se consolidará la hoja de ruta propuesta por la QDR será algo más pequeña que la actual pero con un catálogo de capacidades similar (Tabla 1); que los medidas A2/AD de sus adversarios habrán madurado y que sus fuerzas armadas deberán estar preparadas para responder a múltiples contingencias; es evidente que el país

Technology", War on the Rocks (17 de Noviembre de 2014), en: http://warontherocks.com/2014/11/offset-3-0or-how-i-learned-to-stop-worrying-and-love-commercial-technology). De hecho, ésta es la idea sobre la que se basa el Long Range Research and Development Plan, que pretende apoyar las propuestas tecnológicas de la industria civil del país para madurarlas e integrarlas en los sistemas que serán esenciales para consolidar la tercera estrategia de compensación (DID Staff: "Pentagon Releases Request for Information to Support Its Latest Offset Strategy", Defense Industry Daily, 3 de Diciembre de 2014, en

http://www.defenseindustrydaily.com/pentagon-lrrdp-rfi-offset-028838/).

27 Colom, Guillem: "El desarrollo conceptual de la Revolución en los Asuntos Militares", Revista Científica 'General José María Córdova', vol. 12, no 14 (julio-diciembre 2014), pp. 19-34.

${ }^{28}$ Discurso del Secretario de Defensa Chuck Hagel en la apertura del "Reagan National Defense Forum" (Simy Valley, 15 de noviembre de 2014). En este sentido, véase también: Haddick, Robert: "Preserving U.S. Military Might: How to Make the Third Offset Strategy a Success", The National Interest, 7 de diciembre de 2014, en http://nationalinterest.org/feature/preserving-us-military-might-how-make-the-third-offset-11800.

${ }^{29}$ Hunter, Andrew et alt. (2014): A Recommended Agenda for the Next Secretary of Defense, Washington DC, Center for International and Strategic Studies.

${ }^{30}$ Este modelo se originó durante la Guerra Fría, cuando la Administración Kennedy adoptó el estándar de dos guerras y media - o la capacidad para luchar en dos conflictos regionales y en un tercer conflicto de baja intensidad - para calcular la estructura de fuerzas, el catálogo de capacidades y el patrón de despliegue en tiempo de paz. En 1991 este modelo fue sustituido por el estándar de dos guerras que se mantuvo hasta la Administración Bush, que propuso el modelo 1-4-2-1, donde las fuerzas del país estuvieran en condiciones de defender el territorio nacional, mantener la disuasión en cuatro zonas del planeta, conducir dos campañas simultáneas y vencer definitivamente en una guerra (Metz, Steven (ed.) (2001): Revising the Two MTW Force Shaping Paradigm, Carlisle, Strategic Studies Institute).

31 Más específicamente, la QDR 2014 vuelve al estándar de dos guerras al establecer que Estados Unidos debe estar en condiciones de derrotar decisivamente a un adversario en una guerra y negar los objetivos o imponer costes inaceptables sobre un segundo agresor en otro punto del planeta. Sin embargo, el Panel de Defensa Nacional (op. cit., pp. 24-27) no sólo alerta que la estructura de fuerzas, el catálogo de capacidades y los recortes planteados imposibilitan el logro de este objetivo; sino que tampoco cabe descartar que Washington se vea forzado a combatir - o proporcionar habilitadores clave a sus socios como capacidades ISTAR o medios de ataque estratégico - en varias regiones del globo de manera simultánea como Corea, Mar de la China, Oriente Medio o Europa. Por lo tanto, este informe concluye que si Estados Unidos pretende garantizar su liderazgo en los asuntos globales, este debe disponer de más fuerzas, más capacidades, más tecnología, más disuasión, más alerta temprana y, sobre todo, no asumir que la calidad de la fuerza siempre sustituye la cantidad de la misma. 
necesita plantear un nuevo modelo para proyectar globalmente su poder y satisfacer, con un ejército más pequeño, un mayor número de cometidos ${ }^{32}$.

TABLA 1 - Evolución del volumen de fuerza y estructura de fuerzas (2010-19)

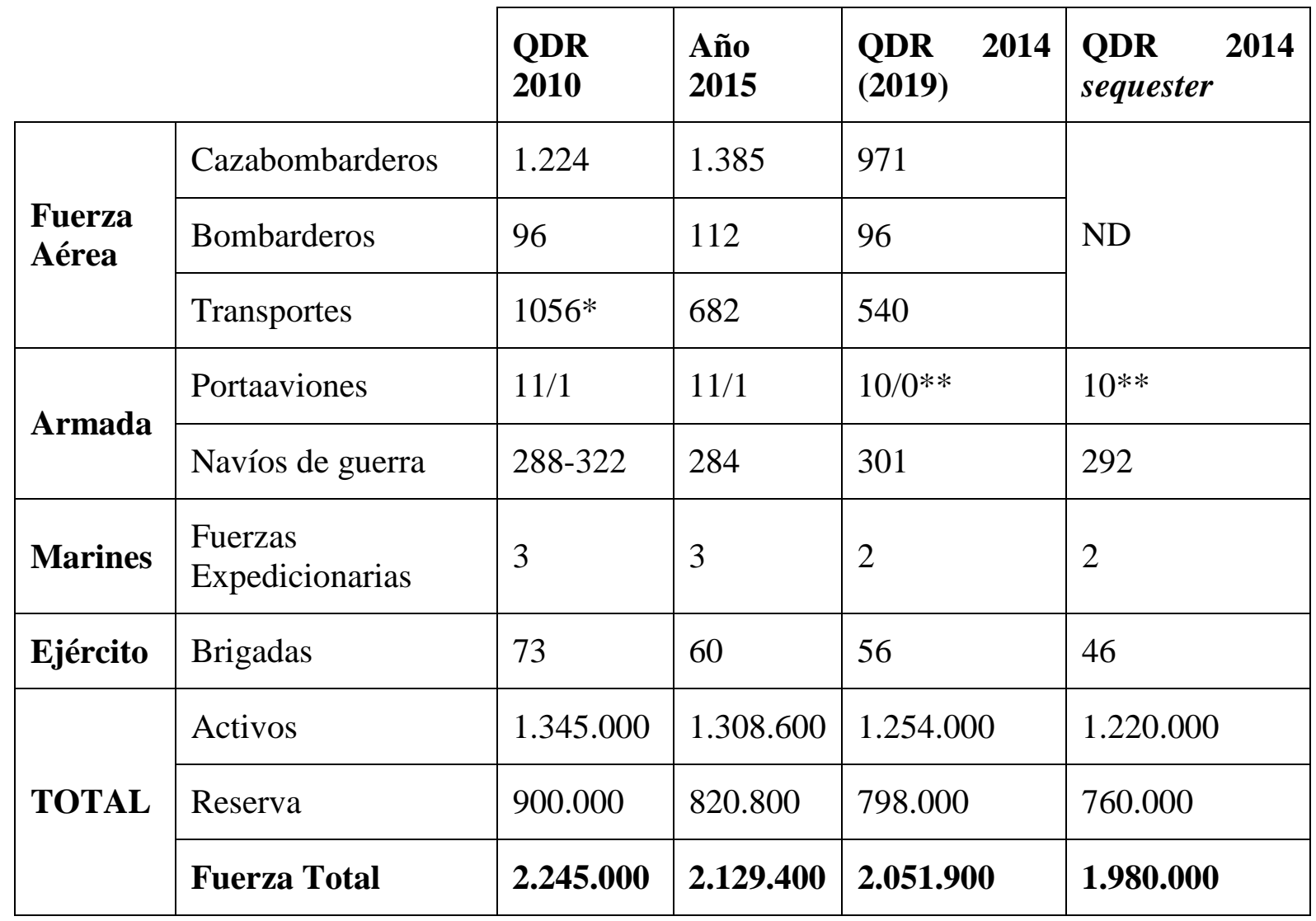

Fuente: elaboración propia a partir de National Defense Panel, op. cit., p. 57

* Esta cifra corresponde a la suma de los aviones de transporte y los aviones de reabastecimiento.

** Estas cifras podrían sufrir variaciones al existir la posibilidad de que el mecanismo de sequestration sobre la base de gasto del Pentágono motivara la baja de uno o dos portaaviones adicionales.

En segundo lugar, porque la supremacía militar que ha proporcionado la RMA de la información durante más de tres décadas parece estar llegando a su fin ${ }^{33}$. Desde la Operación Tormenta del Desierto, los potenciales adversarios del país han estudiado las características

\footnotetext{
${ }^{32}$ Distintas respuestas a este problema pueden hallarse en: Gutzinger, Mark (2014): Shaping America's Future Military: Toward a New Force Planning Construct, Washington DC, Center for Strategic and Budgetary Assessments; Stokes, Jacob y Smith, Julianne (2014): Strategy and Statecraft: An Agenda for the United States in an Era of Compounding Complexity, Washington DC, Center for a New American Security o Conetta, Carl (2012): A Reasonable Defense. A Sustainable Approach to Securing the Nation, Washington DC, Project on Defense Alternatives.

${ }^{33}$ Colom, Guillem (en prensa): Armas inteligentes, drones y ciberguerra: la Revolución en los Asuntos Militares como condicionante de la defensa estadounidense (1981-2014), Madrid, UNISCI-UCM.
} 
del nuevo estilo americano de combatir producto de esta revolución ${ }^{34}$ y se están dotando de los medios tecnológicos (sistemas $C^{4}$ ISTAR para digitalizar el campo de batalla, armas inteligentes para batir con precisión y sin daños colaterales los objetivos enemigos y plataformas furtivas o no-tripuladas para entrar en áreas de riesgo sin ser abatidas) y las capacidades (acción conjunta, operaciones dispersas, fuerzas especiales o ciberguerra) vinculadas con esta revolución ${ }^{35}$. Además, están desarrollando respuestas específicas - como las medidas $\mathrm{A} 2 / \mathrm{AD}$ o las estrategias híbridas ${ }^{36}$ - para impedir que Estados Unidos pueda proyectar su poder bélico y explotar su potencial tecnológico-militar. Dicho de otra forma, tal y como alertó el ex titular de Defensa Chuck Hagel: "...estamos entrando en una nueva era en la que nuestro dominio de los mares, los cielos, el espacio o el ciberespacio no puede continuarse dando por sentado. Aunque todavía mantenemos una gran ventaja tecnológicomilitar frente cualquier adversario, nuestra superioridad futura no es, ni mucho menos, evidente $^{\prime \prime 37}$. Más concretamente, Washington considera que sus fuerzas armadas se enfrentan a cuatro grandes problemas operativos a la hora de proyectar el poder y acceder en entornos con fuertes defensas A2/AD:

- La creciente vulnerabilidad de las instalaciones en las que hay desplegadas fuerzas terrestres, navales o aéreas estadounidenses - como podrían ser el caso de las bases de Guam (Estados Unidos), Diego García (Reino Unido) u Okinawa (Japón) por poner algunos ejemplos - compromete el tradicional modelo de presencia avanzada y de proyección del poder.

- Los adversarios del Estados Unidos se están dotando de medios $C^{4}$ ISTAR estratégicos capaces de detectar, identificar y seguir los movimientos de los buques de superficie desde grandes distancias y están adquiriendo misiles antibuque para destruirlos antes de alcanzar la costa.

- Los aviones no-furtivos, que representan el grueso de la flota aérea del país, son cada vez más vulnerables a las defensas antiaéreas enemigas.

- Los satélites - y con ello las capacidades que éstos proporcionan, desde posicionamiento global y navegación a inteligencia, observación o comunicaciones - son cada vez más vulnerables a ataques físicos o cibernéticos ${ }^{38}$.

\footnotetext{
${ }^{34}$ El término New American Way of War fue concebido en la década de 1990 para definir el estilo militar propio de la RMA que, basado en la superioridad tecnológica, el conocimiento del campo de batalla y la capacidad para realizar ataques de precisión desde grandes distancias, permitiría obtener victorias rápidas, limpias y contundentes frente a cualquier adversario (Lind, Michael (2006): The American Way of Strategy: U.S. Foreign Policy and the American Way of Life, Oxford, Oxford University Press).

35 Horowitz, Michael (2010): The Diffusion of Military Power: Causes and Consequences for International Politics, Princeton: Princeton University Press. Por su parte, en la ponencia titulada "The Third U.S. Offset Strategy and its Implications for Partners and Allies" (Washington DC, 28 de Enero de 2015), el Subsecretario de Defensa Bob Work sostiene que estos desarrollos tecnológicos pueden resumirse en armas nucleares, misiles antibuque, defensas antiaéreas, misiles balísticos y de crucero de largo alcance, ciberfuerzas, sistemas de guerra electrónica y fuerzas de operaciones especiales.

${ }^{36} \mathrm{La}$ integración de la guerra híbrida - que integra procedimientos convencionales con tácticas propias de la guerra irregular (emboscadas, propaganda, agitación, insurgencia, guerra informativa, guerra legal o ciberoperaciones), actos terroristas y conexiones con el crimen organizado - en el marco de la tercera offset puede hallarse en el discurso del Subsecretario Work "The Third U.S. Offset Strategy...", op. cit.

${ }^{37}$ Discurso del Secretario de Defensa Chuck Hagel en la apertura de los "Defense Innovation Days" (Newport, 3 de septiembre de 2014).

${ }^{38}$ Wilson, Tom (2001): Threats to United States Space Capabilities, Washington DC, U.S. Government Printing Office.
} 
En otras palabras, la difusión de las tecnologías de la información (ordenadores, redes de mando, control y comunicaciones, sistemas de geolocalización, inteligencia artificial o cibernética) junto con el desarrollo de medios A2/AD están incrementando la vulnerabilidad de las bases avanzadas, los buques de superficie, los aviones tripulados o los satélites espaciales. Ello compromete la utilidad del paradigma de presencia y proyección del poder estadounidense vigente desde los albores de la Guerra Fría.

En tercer lugar, si Estados Unidos no es capaz de garantizar la consecución de sus objetivos de defensa nacional ni tampoco puede proyectar libremente su poder a cualquier punto del planeta en respuesta a cualquier agresión contra sus intereses, los estrategas del país consideran que ello traerá importantes consecuencias. Para empezar, las medidas A2/AD enemigas plantean unos costes económicos, operativos, estratégicos y políticos que impiden mantener este paradigma de presencia avanzada y proyección del poder ${ }^{39}$. De hecho, el Pentágono no sólo considera inviable incrementar la protección de las infraestructuras terrestres, aeródromos, bases navales, portaaeronaves, fuerzas mecanizadas o aviación táctica frente a las estrategias $\mathrm{A} 2 / \mathrm{AD}$; sino también estima que ninguna defensa activa o pasiva garantizará que Estados Unidos pueda emplear estos medios asumiendo unos niveles de riesgo aceptables ${ }^{40}$. Si esto sucede, su modelo de disuasión convencional se verá comprometido, el impacto de su presencia avanzada sobre la estabilidad regional se verá limitado y su reputación como superpotencia se verá dañada. Y cuando esto se produzca, es muy probable que los aliados y socios estratégicos de Washington - en especial aquellos situados en Asia-Pacífico u Oriente Medio - cuestionen la capacidad estadounidense para defenderlos en caso de necesidad, motivando con ello el surgimiento de un dilema de seguridad susceptible de motivar nuevas carreras de armamentos, facilitar la proliferación nuclear e incluso transformar el actual sistema de alianzas ${ }^{41}$.

En resumen, a día de hoy Estados Unidos se enfrenta a un conjunto de interrogantes estratégicos que impiden mantener su tradicional modelo de presencia avanzada, están erosionando la supremacía militar que brindó la RMA de la información, comprometen el logro de sus objetivos de defensa nacional y pueden altear los cada vez más precarios equilibrios geopolíticos en numerosos puntos del globo. En consecuencia, Washington debe replantear su concepción estratégica para recuperar la ventaja bélica del país frente a cualquier adversario y así mantener intactos sus objetivos de seguridad nacional o bien reducir su nivel de ambición y aceptar que ya ha dejado de ser un poder global ${ }^{42}$.

\footnotetext{
${ }^{39}$ Tangredi, Sam (2013): Anti-Access Warfare: Countering A2/AD Strategies, Annapolis, U.S. Naval Institute Press.

40 "Shortcomings with the Current U.S. Approach to Power Projection", en Martinage, op. cit., pp. 21-38.

${ }^{41}$ Ibid., pp. 63-64.

${ }^{42}$ Aunque la tercera offset constituye el marco que articulará la estrategia global y el planeamiento de la defensa estadounidense para los próximos años, es posible hallar numerosas reflexiones acerca de cómo podría materializarse la Guía Estratégica de la Defensa (2012). En este sentido, obsérvense las ideas de Barry Posen, op. cit.; Hendrix, Henry (2015): Avoiding Trivia: A Strategy for Sustainment and Fiscal Security, Washington DC, Center for a New American Security o Measheimer, John: "America Unhinged", The National Interest, $\mathrm{n}^{\circ} 129$ (Enero-febrero 2014), pp. 9-30. Sin embargo, parece que los estrategas encargados de articular la tercera offset asumen - tal y como recordó Barry Posen hace más de diez años - que la hegemonía estadounidense está vinculada con el control de los espacios comunes como los mares, el aire, el espacio y el ciberespacio (Posen, Barry: "Command of the Commons: The Military Foundation of U.S. Hegemony", International Security, vol. 28, no 1 (Verano 2003), pp. 5-46).
} 


\section{Articulando la tercera estrategia de compensación}

La tercera offset es la respuesta que está articulando el Pentágono para resolver este conjunto de interrogantes estratégicos que comprometen el logro de sus objetivos de seguridad nacional. Fundamentada en la herencia de la revolución de la información y enfocada a explotar el potencial científico-tecnológico del país, esta iniciativa pretende incrementar la brecha de capacidades militares entre Estados Unidos y sus potenciales adversarios, garantizar la capacidad para proyectar su poder a cualquier punto del globo y reforzar los compromisos de seguridad existentes entre Washington y sus aliados. Más concretamente, se pretende que esta estrategia:

- Combine los sistemas heredados - aquellos medios terrestres, navales y aéreos que actualmente se hallan en el inventario militar estadounidense - con el desarrollo de nuevos medios materiales que permitan a las fuerzas armadas del país mantener su brecha cualitativa frente a cualquiera de sus adversarios.

- Limite la dependencia que tiene Estados Unidos de las instalaciones navales, aéreas y terrestres que, situadas en las regiones avanzadas, son vitales para preposicionar hombres y material, garantizar el eficaz sostenimiento de las fuerzas desplegadas y proyectar el poder militar.

- Reduzca la dependencia que tienen las fuerzas armadas del país de las capacidades (observación, reconocimiento, comunicaciones, geolocalización, mando y control, navegación, adquisición de objetivos o meteorología) que proporcionan sus satélites civiles y militares ${ }^{43}$.

- Aproveche la presencia y capacidad de proyección global de su Fuerza Aérea y de su Armada o la eficacia de sus sistemas dirigidos por control remoto o autónomos ${ }^{44}$.

- Explote la capacidad estadounidense para realizar ataques estratégicos de precisión susceptibles de batir cualquier objetivo enemigo tanto dentro como fuera del área de operaciones.

- Modele la nueva carrera de armamentos que se producirá entre Estados Unidos y sus competidores estratégicos mediante la explotación de las áreas tecnológico-militares en las que el país mantiene un claro liderazgo (sistemas no-tripulados, inteligencia artificial, ciberespacio, guerra submarina, ataque estratégico o integración de sistemas) y donde sus adversarios todavía carecen del know-how necesario.

- Aproveche las alianzas, acuerdos o convenios existentes entre Washington y sus socios con el fin de mejorar su posicionamiento estratégico y compartir los costes y responsabilidades de la defensa regional ${ }^{45}$.

Para posibilitar la consecución de estos objetivos, esta estrategia seguirá dos grandes líneas de acción: por un lado, explotará la brecha militar que Estados Unidos mantiene en cinco áreas

\footnotetext{
${ }^{43}$ Este hecho es muy relevante, puesto que Barry Posen (Ibid., pp. 12-14) no sólo considera que el control del espacio es uno de los puntales de la hegemonía americana, sino que George y Meredith Friedman afirman que los satélites y las capacidades que éstos proporcionan son el pilar del estilo militar del país (Friedman, George y Friedman, Meredith (1998): The Future of War: Power, Technology and American World Dominance in the Twenty-First Century, Nueva York, St. Martin's Griffin, p. 303).

${ }^{44}$ Una de las características de los ejércitos del futuro será su progresiva robotización y automatización, que a su vez incrementará su dependencia del ciberespacio para la transmisión de datos (Work, Robert y Brimley, Shawn (2014): 20YY: Preparing for War in the Robotic Age, Washington DC, Center for a New American Security).

${ }^{45}$ Green, Michael; Hicks, Kathleen y Cooper, Zack (2014): Federated Defense in Asia, Washington DC, Center for Strategic and International Studies.
} 
de capacidad $^{46}$ (operaciones no-tripuladas ${ }^{47}$, operaciones navales y aéreas a grandes distancias $^{48}$, operaciones no-observables ${ }^{49}$, guerra submarina ${ }^{50}$ e ingeniería e integración de sistemas ${ }^{51}$ ) para garantizar - con una fuerza conjunta más pequeña pero más tecnificada - la presencia avanzada y la proyección del poder en entornos A2/AD mientras refuerza su liderazgo materia militar y obliga a los potenciales adversarios a iniciar una carrera de armamentos que posiblemente no podrán seguir ${ }^{52}$. Por otro lado, reemplazará el tradicional enfoque a la disuasión convencional basado en la amenaza de una intervención armada coronada por una invasión terrestre para retomar el control y recuperar el statu quo ante bellum, por otro que priorice tanto la disuasión por negación (reduciendo la percepción del enemigo acerca de su capacidad para lograr sus objetivos militares) como la disuasión por castigo (garantizando la capacidad para realizar ataques de represalia contra objetivos de alto valor enemigos con la finalidad de manifestar que cualquier alteración del statu quo entrañará unos costes inasumibles para el atacante $)^{53}$. En cualquier caso, si la disuasión convencional ${ }^{54}$

\footnotetext{
${ }^{46}$ Estas cinco áreas de capacidad - entendidas como el producto resultante de la explotación de nuevas doctrinas, formas de organización, adiestramiento del personal, medios materiales, liderazgo estratégico y enseñanza militar - que deberían guiar tanto la definición de conceptos operativos como el desarrollo de capacidades específicas, son consideradas como core competencies porque poseen un elevado valor añadido y no pueden ser emuladas - al menos por el momento - por los adversarios del país. Obsérvese también que los sistemas sobre los cuales se configuran estas áreas de capacidad son los que Estados Unidos utilizará para modelar la nueva carrera de armamentos y los que orientarán el desarrollo tecnológico hasta 2030. Paradójicamente, la propuesta de gasto del Pentágono para 2016 considera - en línea con los hallazgos de la QDR 2014 - que las key capability areas que requieren el grueso de los fondos son el arsenal nuclear, satélites, defensa antimisiles, ciberseguridad y proyección del poder.
}

${ }^{47}$ El Pentágono pretende incrementar el volumen y alcance de las operaciones no-tripuladas, realizadas éstas por drones furtivos de largo alcance y gran autonomía capaces de reabastecerse en vuelo y operar de forma ininterrumpida durante largos periodos de tiempo para realizar tanto labores de inteligencia, observación y reconocimiento como ataque estratégico; por drones submarinos capaces de operar cerca de las costas enemigas en operaciones de inteligencia o ataque y por drones terrestres de combate.

${ }^{48}$ Éstas son posibles en el aire gracias a la inigualable flota de bombarderos, aviones de reconocimiento, guerra electrónica y aeronaves de reabastecimiento en vuelo; capacidad que se incrementará con la adquisición de nuevos aviones y drones furtivos capaces de llevar a cabo tanto operaciones clandestinas en tiempo de paz como labores de inteligencia y ataque de precisión en caso de guerra. Por su parte, en los océanos éstas son posibles gracias a su imponente flota de superficie y submarina capaz de realizar labores de presencia avanzada y proyección del poder tierra adentro.

${ }^{49}$ Éstas se refieren a la capacidad de sus medios aéreos y submarinos para realizar operaciones encubiertas, furtivas o difíciles de identificar por sus sistemas de detección con mayor efectividad que cualquiera de sus rivales.

${ }^{50}$ La flota submarina estadounidense no sólo es más moderna y capaz que sus adversarios, sino que puede realizar labores de inteligencia, introducción y extracción de fuerzas de operaciones especiales o ataque de precisión. Estas capacidades se verán incrementadas con la compra de nuevas plataformas.

${ }^{51}$ La ingeniería e integración de sistemas no sólo permite conectar todos los elementos de la fuerza - soldados, plataformas, sensores o armas - en un sistema de sistemas que permite combatir en red; sino que también garantiza la conectividad del ejército estadounidense con otras fuerzas aliadas, la fusión de inteligencia de distinta procedencia o el despliegue de redes dinámicas de mando y control.

52 Erwin, Sandra: "Pentagon Mulls Strategy for Next Arms Race", National Defense (Diciembre 2014), en www.nationaldefensemagazine.org/archive/Pages/PentagonMullsStrategyforNext ArmsRace.aspx.

53 Para encuadrar este retorno al modelo de disuasión convencional, es recomendable la lectura de: Gerson, Michael: "Conventional Deterrence in the Second Nuclear Age", Parameters, vol. 39 n 3 (Otoño 2009), pp. 3248 y Knopf, Jeffrey: "The Fourth Wave in Deterrence Research", Contemporary Security Policy, vol. $31, \mathrm{n}^{\circ} 1$ (Abril 2010), pp. 1-33.

${ }^{54}$ Puede parecer paradójico, pero los trabajos que analizan la tercera offset obvian el papel del arsenal atómico como razón última de la disuasión nacional y eje de la disuasión extendida como compromiso del país con la seguridad de sus aliados y socios. En este sentido, aunque la doctrina estadounidense fija que un ataque con este tipo de ingenios podría entrañar una respuesta atómica, el énfasis en los medios convencionales parece sugerir que el país pretende sustituir la disuasión nuclear extendida por la disuasión convencional fuerte como medio para evitar verse envueltos en un conflicto nuclear debido a una crisis limitada en Europa, Oriente Medio o AsiaPacífico. Un interesante recordatorio acerca del papel del arsenal nuclear estadounidense en el marco de esta 
no puede impedir la agresión contra los intereses estadounidenses o sobre los aliados y socios del país, Washington debe ser capaz de responder de forma rápida y decisiva para detener el ataque, forzar el cese de las hostilidades o lograr una victoria clara y resolutiva sobre el enemigo 55 .

Aunque la estrategia de compensación promete resolver los interrogantes estratégicos que debe afrontar Estados Unidos en la posguerra contra el terror, su desarrollo puede estar condicionado por tres factores que pueden comprometer el éxito e incluso motivar el fracaso de este proceso de innovación militar. En primer lugar, en la actualidad el país todavía se encuentra en una compleja situación económica y no puede esperarse que las finanzas del Pentágono experimenten importantes mejoras en los próximos años ${ }^{56}$. Ello contrasta con la aparente vitalidad económica de la República Popular China, que le permite aumentar anualmente un $10 \%$ su gasto en defensa y reducir progresivamente la brecha militar con Estados Unidos ${ }^{57}$. En segundo lugar, en caso de conflicto, las fuerzas armadas del país se hallarían en una situación de desventaja ya que se verían obligadas a proyectar su poder desde pocas bases avanzadas vulnerables a los ataques enemigos. Por último, a diferencia de las offset pasadas - una que desembocó en la represalia masiva y otra que motivó la RMA de la información - que pretendían compensar la superioridad militar convencional de la Unión Soviética en el teatro europeo ${ }^{58}$, la actual pretende garantizar que Estados Unidos pueda proyectar su poder a cualquier punto del globo en respuesta a una amplia gama de contingencias (desde crisis limitadas a guerras convencionales), contra múltiples adversarios (Rusia, China, Irán, Corea del Norte o actores no-estatales con capacidades militares avanzadas) y en distintos escenarios (el Estrecho de Ormuz, el Mar de la China, Taiwán o Centroeuropa $)^{59}$. No obstante, parece evidente que la tercera estrategia de compensación se

estrategia puede hallarse en: Colby, Elbridge (2015): Nuclear Weapons in the Third Offset: Avoiding a Nuclear Blind Spot in the Pentagon's New Initiative, Washington DC, Center for a New American Security.

${ }_{55}$ Sobre la disuasión convencional en el marco de la tercera offset, véase: Manken, Thomas (2014): CostImposing Strategies, a brief primer, Washington DC, Center for a New American Security.

${ }^{56}$ Recuérdese que a mediados de 2011 se aprobó el Budget Control Act of 2011 que reducía la base de gasto militar - entendida ésta como la partida aprobada en el presupuesto federal para garantizar el funcionamiento del Pentágono en condiciones normales - a los 487.000 millones de dólares, una cifra que podría reducirse a la mitad en caso de no contener el déficit público en los siguientes ejercicios. Además la ley introdujo un mecanismo de sequestration de un $7 \%$ adicional sobre el presupuesto base de defensa que se activaría automáticamente si el gobierno y la oposición no lograban consensuar los presupuestos, tal y como sucedió en 2013. Aunque a finales de año se aprobó la Bipartisan Budget Act of 2013 que incrementaba la base de gasto hasta los 526.800 millones para 2014 y 495.000 para 2015. Aunque la QDR 2014 asume estas reducciones y realiza sus planes en base a este escenario, el National Defense Panel se muestra contrario e insta al ejecutivo y legislativo del país a volver a la base de gasto de 2012. No obstante, en la propuesta de presupuestos para 2016 el Pentágono ha planteado una base de gasto de 534.300 millones, bastante mayor que los años anteriores (Office of the Under Secretary of Defense (2015): "FY 2016 Budget Request", Washington DC, U.S. Government Printing Office).

${ }^{57}$ Para la visión oficial estadounidense: Office of the Secretary of Defense (2014): "Military and Security Developments Involving the People's Republic of China 2014", Washington DC, Department of Defense; mientras que para la china Ministry of National Defense (2014): "China's National Defense in 2013", Beijing, Information Office of the State Council of the People's Republic of China. Sin embargo, no pueden descartarse los enormes problemas que comprometen la operatividad del Ejército de Liberación Popular, tal y como sugiere Blasko, Dennis: "Ten Reasons Why China Will Have Trouble Fighting a Modern War", War on the Rocks (18 de Febrero de 2015), en http://warontherocks.com/2015/02/ten-reasons-why-china-will-have-trouble-fighting-amodern-war/.

${ }_{58}^{58}$ Martinage, op. cit., pp. 5-16.

${ }^{59}$ Ponencia de Bob Work, "The Third U.S. Offset Strategy and its Implications for Partners and Allies" (Washington DC, 28 de Enero de 2015). 
orienta primordialmente hacia un hipotético conflicto contra el régimen de Beijín ${ }^{60}-$ en el Mar de la China ${ }^{61}$.

\section{La red global de observación y ataque: pilar de la tercera compensación}

En el centro de esta estrategia de compensación se halla la red global de observación y ataque. Construida a partir de las competencias clave de la tercera offset (acciones notripuladas, operaciones navales y aéreas a gran distancia, operaciones no-observables, guerra submarina e ingeniería e integración de sistemas complejos) y considerada como el principal producto que proporcionará este proceso de innovación militar, esta red será clave para garantizar la capacidad de reconocimiento estratégico, la presencia avanzada y la proyección del poder en ambientes $\mathrm{A}_{2} / \mathrm{AD}^{62}$. Más concretamente, esta red global de observación y ataque se configurará en base a cuatro principios: en primer lugar, el equilibrio entre las plataformas heredadas y los nuevos sistemas de armas para operar con eficacia en toda la gama de las operaciones, especialmente en entornos A2/AD. En segundo lugar, la resiliencia puesto que las fuerzas que constituirán esta red se hallarán geográficamente distribuidas por todo el globo (aunque probablemente los medios más valiosos como los bombarderos estratégicos estarán basados en Estados Unidos), apenas dependerán de las bases y puestos avanzados, estarán protegidas frente a las defensas enemigas y no estarán condicionadas por la degradación de sus habilitadores espaciales y ciberespaciales. En tercer lugar, la disponibilidad, puesto que esta red podrá proyectar las capacidades de observación, reconocimiento, inteligencia, adquisición de objetivos o ataque a cualquier punto del planeta en respuesta a cualquier crisis en cuestión de horas o minutos. Finalmente, la escalabilidad al poder cubrir con los medios disponibles una amplia gama de contingencias que puedan surgir en distintos puntos del globo de forma concurrente.

Esta red global de observación y ataque que servirá como punta de lanza para proporcionar inteligencia global y proyectar el poder en entornos A2/AD debería estar disponible en el horizonte 2030, año en que supuestamente se consolidará la estrategia de compensación $^{63}$. No obstante, la articulación de la tercera offset y la maduración de este concepto de operaciones requerirán que el Pentágono implemente varias iniciativas en materia de investigación y desarrollo, planeamiento estratégico, programación militar o distribución

\footnotetext{
${ }^{60}$ De hecho, desde 1993 - cuando Beijín acuñó el concepto de "guerra limitada en un ambiente de alta tecnología" - China se está preparando para un conflicto de estas características (Newmyer, Jacqueline: "The Revolution in Military Affairs with Chinese Characteristics", Journal of Strategic Studies, vol. 33 n 4 (Agosto 2010), pp. 483-504).

${ }^{61}$ Aunque desde hace mucho tiempo que China se considera el principal antagonista de Estados Unidos y un conflicto contra Beijín constituye una de las principales preocupaciones estratégicas de Washington (Etizoni, Amitai: "Who Authorized Preparations for War with China?", Yale Journal of International Affairs, vol. 8 nº 2 (Verano 2013), pp. 37-51).

${ }^{62}$ Aunque la capacidad de observación y ataque global era uno de los grandes objetivos de la Revolución estadounidense en los Asuntos Militares (Colom, "Armas inteligentes, drones y ciberguerra...", op. cit., pp. 6796), fue sugerida en la hoja de ruta Joint Vision 2010 (1996), debatida en el Panel de Defensa Nacional (1997), planteada por el neoconservador Project for a New American Century (1999) y apadrinada por el Secretario de Defensa Donald Rumsfeld (2001-06), como concepto operativo y área de capacidad comenzará a consolidarse pocos meses antes del lanzamiento de la tercera offset. En este sentido, véase la comparecencia de Shawn Brimley, Vicepresidente del think tank Center for a New American Security, en el Comité del Senado para las Fuerzas Armadas el 16 de Julio de 2014.

${ }^{63}$ Paradójicamente, algunos consideran que la RMA de la información se conseguirá en estas fechas: Watts, Barry (2011): The Maturing Revolution in Military Affairs, Washington DC, Center for Strategic and Budgetary Assessments.
} 
de los recursos ${ }^{64}$. Más específicamente, en el campo armamentístico se han identificado las siguientes prioridades:

- La obtención de capacidades anti-satélite avanzadas que refuercen la disuasión del país frente ataques contra estos sistemas. No obstante, la centralidad de los satélites en la guerra moderna y su valor como multiplicadores de las operaciones militares recomiendan implementar medidas orientadas a reforzar la resiliencia y reducir la dependencia estadounidense de estos medios frente a su degradación, inutilización o destrucción. Ello obligará a hallar alternativas al Sistema de Posicionamiento Global (GPS) para la navegación de precisión, desplegar drones estratégicos para realizar labores de observación, reconocimiento o adquisición de objetivos y desarrollar un sistema complementario a las comunicaciones por satélite ${ }^{65}$.

- El aumento de la presencia, duración y cobertura geográfica de la flota submarina estadounidense gracias al desarrollo de drones submarinos furtivos de largo alcance y gran autonomía capaces de operar remotamente - y en un futuro autónomamente - en cualquier punto del océano. Ello requerirá desarrollar baterías de alta intensidad, sistemas de comunicación, navegación, medios de propulsión, inteligencia artificial o sensores avanzados ${ }^{66}$.

- El incremento de la potencia de fuego de los submarinos nucleares de ataque de la clase Virginia ampliando su capacidad para batir objetivos terrestres ${ }^{67}$, desarrollando módulos logísticos y plataformas lanzamisiles remolcadas ${ }^{68}$, modificando los misiles de crucero Tomahawk y los misiles antiaéreos Standard para batir una mayor gama de blancos (buques, satélites, rádares, búnkeres, etc.) y emprender el desarrollo de misiles balísticos convencionales de medio alcance lanzados desde submarino ${ }^{69}$.

- La ampliación de la cobertura geográfica de las redes de sensores acústicos que el Pentágono mantiene desplegados en la superficie del mar y en el fondo de los océanos para detectar cualquier movimiento extraño.

- La adquisición de minas terrestres, navales, submarinas y de lanzamiento aéreo para incrementar las defensas de las instalaciones avanzadas.

\footnotetext{
${ }^{64}$ Para una visión general sobre los principales retos en materia de programación militar, véase: Brimley, Shawn et alt. (2015): Ideas in Action: Suggestions for the 25th Secretary of Defense, Washington DC, Center for a New American Security. Sin embargo, para un análisis más detallado sobre las iniciativas en esta materia que el flamante Secretario de Defensa Ashton Carter debería implementar, obsérvese el siguiente trabajo: Brimley, Shawn; Hendrix, Jerry y Scharre, Paul: "Ash Carter: Invest in the 3rd Offset Strategy", Real Clear Defense (23 de Febrero de 2015), en: www.realcleardefense.com/articles/2015/02/23/ash_carter_invest_in_the_offset_strategy_107654.html.

${ }^{65}$ Para una visión general de los riesgos que se ciernen sobre las capacidades militares espaciales y las posibles acciones para minimizarlos, véase: Pawlikowski, Ellen; Loverro, Doug y Cristler, Tom: "Space Disruptive Challenges, New Opportunities, and New Strategies", Strategic Studies Quarterly, vol. 6 n $^{\circ} 1$ (Primavera de 2012), pp. 27-54.

${ }^{66}$ Un interesante análisis sobre estos aspectos puede hallarse en: Clark, Bryan (2015): The Emerging Era in Undersea Warfare, Washington DC: Center for Strategic and Budgetary Assessments.

${ }^{67}$ Este incremento de la capacidad de ataque a tierra se conseguirá añadiendo una sección al casco del submarino que albergará las celdas de los misiles (Hasslinger, Karl y Pavlos, John: "The Virginia Payload Module: a Revolutionary Concept for Attack Submarines", Undersea Warfare, $\mathrm{n}^{\circ} 47$ (Invierno 2012), en: http://www.public.navy.mil/subfor/underseawarfaremagazine/issues/archives/issue 47/virginia.html).

${ }^{68}$ En este sentido, véase cómo podrían integrarse estos módulos lanzamisiles en la estructura de la flota: Holmes, James: "Distributed Lethality: The Navy's Fix for Anti-Access?", War on the Rocks, 19 de enero de 2015, en http://warontherocks.com/2015/01/distributed-lethality-the-navys-fix-for-anti-access/.

${ }^{69}$ Una visión complementaria puede hallarse en: Clark, Bryan (2014): Commanding the Seas: A Plan to Reinvigorate U.S. Navy Surface Warfare, Washington DC, Center for Strategic and Budgetary Assessments.
} 
- El desarrollo de armas antisubmarinas inteligentes de largo alcance.

- La aceleración del desarrollo de armas electromagnéticas y de energía dirigida que permitan incrementar las defensas de los buques y de las instalaciones avanzadas frente ataques enemigos ${ }^{70}$.

- La investigación y desarrollo de nuevos sistemas de armas como cañones de energía dirigida, equipos de guerra electrónica, señuelos o ciberarmas que permitan destruir o degradar los sensores enemigos ${ }^{71}$.

- El desarrollo de sistemas no-tripulados autónomos de reabastecimiento en vuelo.

- El impulso e incremento de las opciones de compra del programa Long Range Strike Bomber (LRS-B) para dotar a la Fuerza Aérea de un nuevo bombardero estratégico invisible que complemente a la actual flota de $B-2$ Spirit $^{72}$.

- La adquisición de sistemas no-tripulados de ataque basados en tierra o embarcados optimizados para batir objetivos altamente móviles en entornos de alto riesgo ${ }^{73}$.

- La compra de drones furtivos de elevada autonomía capaces de operar a gran altura para realizar labores de observación y reconocimiento en entornos de riesgo.

- El desarrollo de redes anti-acceso y de negación de área que, compartidas con los socios y aliados de Washington, refuercen las capacidades de autodefensa de estos países y permitan a Estados Unidos continuar manteniendo bases avanzadas desde las cuales lanzar cualquier acción bélica ${ }^{74}$.

\section{Implementando la tercera estrategia de compensación}

Considerada como la respuesta a los interrogantes estratégicos que afectan a Estados Unidos en la posguerra contra el terror, la tercera estrategia de compensación guiará el planeamiento de la defensa del país durante los próximos quince años. Sin embargo, teniendo en cuenta que ésta comenzará a implementarse en un entorno presupuestario relativamente restrictivo (al menos en el quinquenio $2015-20^{75}$ ), que algunos proyectos de modernización no pueden

\footnotetext{
${ }^{70}$ Gunzinger, Mark y Dougherty, Chris (2012): Changing the Game: The Promise of Directed-Energy Weapons, Washington DC, Center for Strategic and Budgetary Assessments.

${ }^{71}$ Mención aparte requiere el llamado Plan X (DARPA-BAA-13-02) desarrollado desde 2012 por DARPA para crear una nueva generación de ciberarmas. Para más información, véase http://www.darpa.mil/ Our_Work/I2O/Programs/Plan_X.aspx.

${ }_{72}$ Paradójicamente, las tecnologías y los diseños furtivos que constituyeron uno de los pilares de la RMA de la información son cada vez menos invisibles para los sistemas de detección avanzados (Metrick, Andrew: "A Cold War Legacy: the Decline of Stealth", War on the Rocks, 20 de Enero de 2015, en http://warontherocks.com/2015/01/a-cold-war-legacy-the-decline-of-stealth/).

${ }^{73}$ Una visión panorámica de los proyectos actualmente en desarrollo puede hallarse en: Department of Defense (2013): Unmanned Systems Integrations Roadmap FY2013-2038, Washington DC, U.S. Government Printing Office.

${ }^{74}$ De hecho, se propone que estas redes integren sistemas de alerta temprana, nodos cibernéticos y una amplia gama de defensas (misiles balísticos y de crucero, armas antisubmarinas, misiles anti-buque y defensas antiaéreas y antimisil). De hecho, es aquí donde el Ejército de Tierra estadounidense intentó hallar su papel dentro de la ya descartada doctrina de Batalla Aero-Naval (Crowter, Alex (2013): The Army Should Embrace $A 2 / A D$, Carlisle Barracks, U.S. Army Strategic Studies Institute). Hoy en día, el Ejército pretende hacerse un hueco en la tercera compensación reivindicando su valor como medio para superar las medidas A2/AD y participar en el concepto de Acceso Operacional Conjunto que con toda probabilidad se consolidará como uno de los puntales de esta offset. En este sentido, véase: Department of Defense (2011): "Joint Operational Access Concept", Washington DC, U.S. Government Printing Office.

${ }^{75}$ Para conocer las proyecciones de gasto del Pentágono hasta 2020, véase: Under Secretary of Defense, op. cit., p. 1(5).
} 
dilatarse (caso del arsenal nuclear, el escudo antimisiles, los satélites o las cibercapacidades) ${ }^{76}$ y que tanto el desarrollo de los proyectos como la obtención de los programas no podrá sufragarse incrementando el gasto o solicitando créditos extraordinarios, el Pentágono intentará combinar - en la medida de lo posible - los medios materiales heredados de la Guerra Fría o que han entrado en servicio desde $1991^{77}$ con el desarrollo de los nuevos sistemas de armas - drones estratégicos furtivos, bombarderos invisibles, robots de combate, ciberarmas, sistemas $C^{4}$ ISTAR, cañones electromagnéticos, etc. - que se convertirán en los puntales tecnológicos de las guerras del futuro. Más específicamente, las principales prioridades en materia de investigación y desarrollo - condicionadas éstas a los hallazgos del Programa para la Investigación y Desarrollo a Largo Plazo ${ }^{78}$ - y adquisición de armamento y material para los próximos ejercicios presupuestarios son las siguientes:

- Sistemas aéreos furtivos, tripulados o robotizados, de largo alcance y capaces de realizar labores de alerta temprana, observación, reconocimiento y adquisición de objetivos en ambientes de alto riesgo.

- Nuevos enfoques a las operaciones aéreas que resuelvan los problemas operativos planteados por las estrategias A2/AD: la profusión de defensas aéreas enemigas, la dificultad para operar desde bases avanzadas, la vulnerabilidad de los aviones de reabastecimiento en vuelo o el limitado alcance de la aviación táctica.

- Incrementar la capacidad para lanzar ataques de precisión desde grandes distancias. En este sentido, no parece extraño que el Ejército de Tierra esté planteando dotarse de misiles balísticos de alcance intermedio y de crucero para hallar su sitio en la tercera offset ${ }^{79}$; la Fuerza Aérea proponga integrar los bombarderos $L R S-B$ y drones estratégicos (resucitando el programa $M Q-X$, desarrollando nuevas versiones del Avenger, armando el $R Q-170$ Sentinel y poniendo en servicio el $X-47 B$ ) para complementar a la actual flota de $B-1, B-2$ y $B-52^{80}$ y la Armada busque soluciones - como desarrollar módulos de misiles remolcados e incrementar la pegada de los submarinos de ataque Virginia con más misiles de crucero - para solventar la importante pérdida de potencia de fuego que se producirá con la baja de los cuatro submarinos Ohio armados con Tomahawk en $2028^{81}$.

\footnotetext{
${ }^{76}$ Ello se deduce tanto de los planteamientos expuestos por la Revisión Cuatrienal de la Defensa 2014 y ratificados por el Panel de Defensa Nacional como por las partidas de gasto proyectadas para el quinquenio 2015-20.

${ }^{77}$ Precisamente, muchos de los sistemas de armas que entraron en servicio en torno a aquellas fechas - como el tanque M1-Abrams, el helicóptero de ataque AH-64 Apache, el misil de crucero Tomahawk, los aviones invisibles F-117 Nighthawk y B-2 Spirit o el sistema antiaéreo AEGIS que montan muchos navíos de guerra, por poner algunos ejemplos - eran producto de la segunda offset y constituyeron las bases de la RMA de la Información (Colom, "Armas inteligentes, drones y ciberguerra...", op. cit., pp. 101-128).

${ }^{78}$ Las cinco áreas propuestas por este programa son: espacio, tecnologías submarinas, dominio del aire y ataque, defensa aérea y antimisil u otros conceptos tecnológicos. Un análisis más extenso de estas áreas tecnológicas puede hallarse en: Erwin, Sandra: "Defense Department Takes Steps to Energize Cutting-Edge Research", National Defense (Marzo 2015), en:

www.nationaldefensemagazine.org/archive/2015

/March/Pages/DefenseDepartmentTakesStepsToEnergizeCutting-EdgeResearch.aspx.

${ }^{79}$ Gordon, John y Matsumura, John (2013): The Army's Role in Overcoming Anti-Access and Area Denial Challenges, Santa Monica, RAND Corporation.

${ }^{80}$ Gertler, Jeremiah (2014): U.S. Air Force Bomber Sustainment and Modernization: Background and Issues for Congress, Washington DC: Congressional Research Service.

${ }^{81}$ Estos planteamientos parecen estar en línea con el controvertido enfoque propuesto por el Almirante Greenert de simplificar el diseño de las plataformas (buques y submarinos) para convertirlas en meros portadores de armas y drones de largo alcance (Greenert, Jonathan: "Payloads Over Platforms: Charting a New Course", Proceedings, vol. 138, $\mathrm{n}^{\circ} 1.313$ (Julio 2012), pp. 16-23). Igualmente, puede argumentarse que tanto los
} 
- Priorizar el desarrollo y entrada en servicio del bombardero LRS-B y nuevos drones capaces de batir con precisión objetivos móviles, protegidos o de alto valor en entornos de alto riesgo ${ }^{82}$.

- Incrementar la capacidad de los bombarderos invisibles $B-2$ - y su complemento natural $L R S-B$ - para realizar ataques en profundidad contra objetivos altamente protegidos y enterrados en entornos A2/AD; y desarrollar nuevos misiles lanzados desde submarino optimizados para tal fin ${ }^{83}$.

Sin embargo, el desarrollo de esta estrategia de compensación - y más concretamente la adquisición de los medios materiales, la obtención de los habilitadores necesarios o la investigación de tecnologías potencialmente revolucionarias - en un contexto marcado por la escasez de recursos financieros, humanos y materiales requerirá que el Pentágono implemente medidas impopulares que suscitarán profundas controversias entre la clase política e industrial y resistencias corporativas entre el estamento militar. Por un lado, se deberá modificar la estructura de fuerzas, el catálogo de capacidades, los patrones de despliegue y los equilibrios institucionales entre los tres ejércitos fijados por la Revisión Cuatrienal de la Defensa para el periodo 2014-19 ${ }^{84}$. Por otro lado, se deberá replantear la estructura de gasto del Pentágono para garantizar la financiación de los proyectos armamentísticos vinculados con la tercera offset ${ }^{85}$. En efecto, el desarrollo y adquisición de estos programas requerirá unos fondos que deberán obtenerse mediante la reducción de la estructura de fuerzas, la racionalización de infraestructuras, procesos y programas, la externalización de servicios ${ }^{86}$ o la suspensión como paso previo a la baja definitiva - de los planes de modernización de aquellos medios materiales considerados obsoletos para la nueva estrategia e incapaces de garantizar la supervivencia en entornos $\mathrm{A} 2 / \mathrm{AD}$, como pueden ser la aviación de reconocimiento no-furtiva, la aviación táctica tripulada o las fuerzas mecanizadas ${ }^{87}$. Más específicamente, las medidas que uno de los máximos exponentes de la tercera offset está barajando - y que chocan

submarinos Ohio con misiles de crucero como los módulos remolcados lanzamisiles son herederos directos del proyecto de buque Arsenal que articuló la pasada RMA naval. Concebido como una plataforma semi-furtiva con un desplazamiento comprendido entre las 20.000 y 30.000 toneladas, fuertemente protegido y armado con más de 500 misiles para batir con precisión los objetivos terrestres, este buque era considerado como el acorazado del siglo XXI y la estrella del proyecto CS-21 para dotar a la Armada de una familia de buques optimizados para el ataque a tierra.

${ }^{82}$ Para una visión panorámica sobre los proyectos y planes de desarrollo aeronáutico a largo plazo, véase: Department of Defense (2013): "Annual Aviation Inventory and Funding Plan Fiscal Years (FY) 2014-2043", Washington DC. U.S. Government Printing Office.

${ }^{83}$ Sobre la controversia generada por el $L R S-B$, véase: Haddick, Robert: "Why the New Bomber is a Good Investment", War on the Rocks, 26 de febrero de 2015, en http://warontherocks.com/2015/02 /why-the-newbomber-is-a-good-investment/.

${ }^{84}$ Leopold, George: "Amid cuts, DoD focuses of next offset strategy", Defense Systems, 30 de Enero de 2015, en http://defensesystems.com/articles/2015/01/30/dod-work-new-offset-strategy.aspx.

${ }^{85}$ Brimley et al., op. cit., pp. 9-13.

${ }^{86}$ Paradójicamente, la mayoría de estas propuestas orientadas a racionalizar y abaratar el funcionamiento del Pentágono no son exclusivas de la offset, sino que son una tónica latente desde el final de la Guerra Fría. No obstante, es probable que constituyan algunas de las prioridades del nuevo titular de Defensa (Carter, Ashton: "Running the Pentagon Right: How to Get the Troops What They Need", Foreign Affairs, vol. 93 n $^{\circ} 1$ (EneroFebrero 2014), pp. 13-28.

${ }^{87}$ Martinage, op. cit., pp. 20. Paradójicamente, mientras el autor considera las fuerzas mecanizadas como "sunset capabilities", el Panel de Defensa Nacional ("Ensuring a String Defense...", op. cit., p. 44) las califica como algo esencial en la estrategia estadounidense en línea con los planteamientos recogidos por las máximas autoridades del Ejército de Tierra, el Cuerpo de Marines y el Mando de Operaciones Especiales (Odierno, Raymond; Amos, James y McRaven, William (2013): Strategic Landpower: Winning the Clash of Wills, Washington DC, Department of the Army). 
frontalmente tanto con el modelo actual de presencia y proyección del poder como con las líneas planteadas por la por la Revisión Cuatrienal de la Defensa y avaladas por el Panel de Defensa Nacional ${ }^{88}$ - para financiar la construcción de esta estrategia son las siguientes ${ }^{89}$ :

- Reducir la flota de cazabombarderos de la Fuerza Aérea, la Armada y el Cuerpo de Marines ${ }^{90}$ mediante la modernización de los F-18E/F Hornet al estándar Advanced Super Hornet, la reducción de las opciones de compra del F-35 Lightning (incluida la cancelación del $F-35 C$ embarcado) y su sustitución por drones furtivos $X-47^{91}$.

- Eliminar uno de los portaaviones actualmente en servicio ${ }^{92}$.

- Reducir tanto las opciones de compra como las modernizaciones propuestas de los destructores de la clase Arleigh Burke, espina dorsal de la Armada.

- Reducir el volumen de fuerzas del Ejército y aplazar los planes de modernización de los sistemas terrestres, especialmente de los medios mecanizados ${ }^{93}$.

- Construir Bases Flotantes Avanzadas (AFSB) para la conducción de operaciones anfibias y el preposicionamiento de material y Buques Conjuntos de Alta Velocidad (JHSV) para el transporte de tropas al teatro de operaciones en detrimento de otros buques anfibios más caros, como pueden ser los proyectos $L H-X$ y $L H A^{94}$.

- Cancelar el Vehículo de Combate Anfibio (ACV) del Cuerpo de Marines.

- Aumentar las defensas pasivas de las bases avanzadas - blindando las instalaciones, dispersando las fuerzas o engañando a los sistemas de observación - frente ataques enemigos mientras se procede al desarrollo de las redes anti-acceso y de negación de área con los aliados y socios estratégicos de Washington.

\section{Conclusiones}

Todavía es pronto para establecer un conjunto de conclusiones formales acerca de la composición final y configuración definitiva de la tercera estrategia de compensación estadounidense. En primer lugar, porque el Programa para la Investigación y Desarrollo a Largo Plazo - que liderará la innovación militar del país en materia terrestre, naval, aérea, espacial y ciberespacial junto con la Agencia de Investigación de Proyectos de Defensa Avanzados - iniciará su andadura durante el segundo semestre de 2015. En segundo lugar, porque el flamante Secretario de Defensa Ashton Carter todavía no ha expuesto su concepción

\footnotetext{
${ }^{88}$ Department of Defense, "Quadrennial Defense...", op. cit., pp. 39-41 y National Defense Panel, "Ensuring a Strong Defense...", op. cit., pp. 44-51.

${ }^{89}$ Martinage, op. cit., p. 69.

${ }^{90}$ Paradójicamente, la reducción de los planes de compra de los aviones $F-18 E / F$ y $F-35$ y la adquisición de drones armados fue propuesta por primera vez en 1997 (National Defense Panel, "Transforming Defense...", op. cit., pp. 41-48).

${ }^{91}$ Sweetman, Bill: "New Strategy Would Cut F-35s, Boost Bombers and UAVs", Aviation Week, 31 de Octubre de 2014, en www.aviationweek.com/defense/new-strategy-would-cut-f-35s-boost-bombers.

${ }^{92}$ La Tabla 1 muestra la fluctuación del número de portaaviones - punta de lanza de la proyección naval estadounidense - desde 2010 hasta 2019. En este sentido, es preciso apuntar que el Panel de Defensa Nacional de 1997 ya recomendaba cancelar el último portaaviones de la clase Nimitz, la adquisición de buques Arsenal y la redefinición de los portaaeronaves $C V X$ (National Defense Panel, "Transforming Defense...", op. cit., pp. 4148).

${ }^{93}$ Estas mismas propuestas también se habían planteado en 1997 (Ibíd., pp. 44-46).

${ }^{94}$ Estos requerimientos ya fueron identificados por la Armada hace más de una década (Department of the Navy (2002): "Sea Power 21", Washington DC, U.S. Goverment Printing Office).
} 
personal acerca de esta estrategia y el proyecto de gasto de su Departamento para 2016 - el primero que se aprobará tras el lanzamiento de la tercera offset - parece buscar un compromiso entre los proyectos en curso, los planes de modernización urgentes (como puede ser el arsenal nuclear o la defensa antimisil) y los programas futuros. Finalmente, porque las fuerzas armadas - el Ejército de Tierra como el gran damnificado de la offset y la Fuerza Aérea o la Armada para salvaguardar sus intereses corporativos frente a la aparente obsolescencia de la aviación tripulada y la flota de superficie - todavía no se han pronunciado acerca de su contribución específica en la estrategia de compensación. Aunque estos elementos impiden plantear una conclusión definitiva acerca de la tercera offset, lo cierto es que esta iniciativa centrará las actividades que realizará el Pentágono durante los próximos quince años.

Fundamentada en las capacidades tecnológicas del país, planteada para redefinir el modelo de proyección del poder militar, encaminada a garantizar la capacidad de acceso a cualquier punto del planeta con independencia de las estrategias A2/AD desplegadas por sus enemigos y orientada tanto a reforzar los vínculos de seguridad con sus aliados y socios estratégicos como forzar a sus potenciales adversarios a emprender una nueva carrera de armamentos que sus complejos militares-industriales posiblemente no podrán mantener, la consecución de la tercera offset motivará el desarrollo de nuevos conceptos operativos, la generación de nuevas capacidades militares y la consolidación de nuevos estilos de concebir, planear y conducir la guerra en la tierra, los mares, el aire, el espacio y el ciberespacio. Asimismo, la configuración de la offset revitalizará los debates acerca de la gestación de una nueva Revolución en los Asuntos Militares capaz de transformar el arte bélico y cuyo logro podría proporcionar a Estados Unidos la supremacía militar frente a sus adversarios hasta que éstos se dotaran - tal y como ha sucedido con las plataformas furtivas, vehículos notripulados, armas inteligentes, sistemas $\mathrm{C}^{4}$ ISTAR o misiles de crucero - de las capacidades militares relacionadas con esta nueva revolución motivada por la consolidación de la tercera offset o diseñaran medidas encaminadas - como han sido las amenazas híbridas o las estrategias $\mathrm{A} 2 / \mathrm{AD}$ - a limitar las ventajas estratégicas que ésta proporcionaría.

No obstante, todavía quedan demasiadas preguntas por responder. En primer lugar, la no-inclusión en la tercera estrategia de compensación de las armas hipersónicas - y más concretamente del proyecto Prompt Global Strike para dotarse de vectores capaces de alcanzar cualquier punto del planeta en minutos ${ }^{95}$ - que permitirían incrementar tanto la disuasión convencional como apoyar la consolidación de la red global de observación y ataque. En segundo lugar, las semejanzas que la estrategia tiene con los planteamientos del Panel de Defensa Nacional de 1997 (como los materiales estimados obsoletos o las tecnologías potencialmente revolucionarias), con algunas propuestas del Proyecto para un Nuevo Siglo Americano en 1999 (en materia de ataque estratégico de precisión o bombarderos furtivos) ${ }^{96}$ o con los planes transformadores que el controvertido Donald Rumsfeld intentó implementar en 2001 (en relación a la automatización y robotización, proyección del poder en ambientes $\mathrm{A} 2 / \mathrm{AD}$, defensa de misiles u observación y ataque global) ${ }^{97}$ sugieren que esta offset pretende resolver unos problemas ya identificados en la inmediata posguerra fría y adoptar unos enfoques ya concebidos en la pasada RMA. Finalmente, los difíciles equilibrios que deberán alcanzarse entre las viejas y las nuevas capacidades; la integración de las

\footnotetext{
${ }^{95}$ Woolf, Amy (2015): Conventional Prompt Global Strike and Long Range Ballistic Missiles Background and Issues, Washington DC, Congressional Research Service.

${ }^{96}$ Donnelly, Thomas (dir.) (1999): Rebuilding America's Defenses: Strategy, Forces and Resources for a New Century, Washington DC, Project for a New American Century.

${ }^{97}$ Spring, Dale: "Rumsfeld as Secretary of Defense", en Cimbala, Stephen (ed.) (2010): The George W. Bush Defense Program: Policy, Strategy \& War, Washington DC, Potomac Books, pp. 77-100 y Colom, "Armas Inteligentes, Drones...", op. cit., pp. 77-98.
} 
lecciones aprendidas de la Guerra contra el Terror en la estrategia de compensación; las resistencias corporativas que se producirán entre los ejércitos cuando el Pentágono proceda a su implementación; el coste económico, los riesgos estratégicos y las implicaciones políticas que tendrá este ambicioso proceso de innovación militar; la integración de la disuasión nuclear en el marco de esta estrategia o la brecha de capacidades que se producirá entre Estados Unidos y sus aliados o socios estratégicos cuando los nuevos materiales se integren en el catálogo militar americano.

La tercera estrategia de compensación es la llave que ha forjado Estados Unidos para garantizar su supremacía militar. Su desarrollo guiará el planeamiento de la defensa del país y su consolidación podrá motivar una nueva Revolución en los Asuntos Militares. Queda por ver cómo evolucionará este proceso de innovación militar y cuáles serán las respuestas que los competidores de Washington plantearán para limitar su impacto. Las bases conceptuales de la guerra del futuro ya se han fijado y solamente queda esperar su consolidación. 